\title{
Vulnerability and the Best Interests of the Child in Tobacco Control
}

\author{
Marie Elske C. Gispen \\ Fellow, Global Health Law Groningen Research Centre, Department of \\ Transboundary Legal Studies, Faculty of Law, University of Groningen, \\ Groningen, The Netherlands \\ mec.gispen@gmail.com
}

\begin{abstract}
The vulnerability of individuals is often used as a springboard to call upon additional rights protection or to scale up interventions. This is also the case in child health and tobacco control research. While human rights law is generally a strong mechanism to support such calls, critics like Martha Fineman question specific understandings of vulnerability within human rights law. Against this backdrop, the article analyses the usefulness of relying on vulnerability in human rights law to argue for better rights protection. The article concludes that Article 3 CRC - reflecting the best interests of the child norm - seems a suitable "solution" to Fineman's critique on the notion of vulnerability in human rights law. Finally, the universal and particular vulnerabilities of children in relation to tobacco-related harm can be a springboard into rights protection but are not the principle legal source that require governments to break down structural health inequalities.
\end{abstract}

\section{Keywords}

children's rights - vulnerability - best interests of the child - health law and policy tobacco control

\section{$1 \quad$ Introduction}

According to the World Health Organization (WHO), approximately 7 million people die each year because of tobacco-related diseases including cancer 
and cardiovascular diseases (WHO, 2018). ${ }^{1}$ Whilst most tobacco-related health infirmity affects adults, the so-called tobacco epidemic roots in childhood and likewise seriously affects child health and development. Indeed, children are vulnerable to tobacco-related harm across the entire tobacco supply chain and at all stages of development (Hofhuis et al., 2003; Makadia et al., 2017; WHO, 2018; see also Gispen and Toebes, 2019).

In general, in research and in practice, the vulnerability of individuals or groups of individuals is often used as a springboard to call upon law and policymakers to scale up interventions, or, as Virokannas and colleagues state, 'to justify the right to receive certain benefits or to gain access to services or treatment' (Virokannas et al., 2018: 2). In child health and tobacco control research, specifically, Been and colleagues stressed that children are particularly vulnerable to secondhand-smoke (sHS) and found that smoke-free legislation positively impacted on perinatal and child health (Been et al, 2014). Hence, they concluded that their study, 'provides strong support for wHO recommendations to create smoke-free environments' (Been et al., 2014: 1549). In response to such call for action, human rights law may be an important vehicle in achieving health equality and may be a powerful legal mechanism to improve the protection of children in tobacco control (Toebes et al., 2018; Gispen and Toebes, 2019). However, vulnerability is a complex and contested norm in general, but also specifically in human rights discourse.

Critics like Fineman, and Peroni and Timmer, for example, question whether specific understandings of vulnerability across the realm of human rights increase instead of decrease the presumed vulnerable position of (those part of a) specific marginalised group(s) (Fineman, 2008-20o9: 8-9; Peroni and Timmer, 2013:1057, 1085). ${ }^{2}$ More specifically, Flegar holds that, 'references to vulnerability can sometimes lend to support to arguments for high levels of protection but the vulnerability label can just as easily become a mechanism

1 This article is based on a poster presented at the 17 th World Conference on Tobacco or Health, held in Cape Town (SA) from 7-9 March 2018. See M.E.C. Gispen, "Leaving no one behind": the vulnerability of children from low SEs households suffering from tobacco-related harm in light of human rights and social justice' (2018) 16 Tobacco Induced Diseases 355 (meeting abstract PS-1171-5). While largely similar in nature and design, based on feedback and further research, a slightly wider approach and title was chosen for this final paper. The author wishes to thank Veronica Flegar, Heleen Weyers, Deryck Beyleveld, and Brigit Toebes for their helpful feedback and Nicole Rusli for editorial assistance. The author remains responsible for any errors or mistakes. The views expressed in this article are those of the author and not necessarily those of the organisation to which the author is affiliated. This chapter is part of the author's previous academic work and by no means relates to the author's current position.

2 See for a summary of criticism of the notion of vulnerability and its potentially counterproductive use in research, policy, and practice, Virokannas et al., 2018. 
to support policy and legal arguments for social control' (Flegar, 2018: 375). The potentially positive and negative implications of the notion of vulnerability in a rights-based context raises questions about the usefulness of relying on the vulnerability of children to call for and justify additional rights protection in general, but also as relevant to tobacco control. In other words, could the notion of vulnerability from a legal perspective foster adopting health laws and policies to protect children against tobacco-related health infirmity?

The article submits that the best interests of the child norm provides a unique legal basis within the 1989 Convention on the Rights of the Child (CRC) to address - formally and substantively - their specific contexts along their developmental process. In other words, it requires taking into account their vulnerability as inevitable and permanent state of all beings, but also factors of dependency and resilience that may vary per context (Flegar and Iedema, 2019: 5). The article finally submits that the best interests of the child is the legal basis for, and thus a cornerstone in, addressing the universal and particular vulnerabilities of children in health law and policy including tobacco control. Yet, while acknowledging some of the constraints of implementing Fineman's vulnerability approach in current human rights law, it thus maintains that the best interests of the child norm could largely remedy such gaps.

The article is based on legal analysis. Methods include literature research and interpretation of human rights documents - specifically those developed within the context of the CRC. ${ }^{3}$ Moreover, the approach taken in this article is limited to addressing vulnerability as proposed by Fineman and others who have immediately built on her theory. For reasons of scope and focus, the paper does not take into account other interpretations of vulnerability as developed in ethics and (political and moral) philosophy more broadly, nor does it build on specific policy approaches to vulnerability.

The article breaks down in two main sections. First, the article commences with analysing vulnerability as proposed by Fineman. It frames the vulnerability of children to tobacco-related harm in this context, and reflects on the potential constraints of such an approach in human rights law. Second, the article analyses the normative scope and content of Article 3 CRC in order to reflect on if and how Fineman's theory of vulnerability could be embedded in the legal realm of the CRC. The article ultimately applies the notion of vulnerability and the BIC-norm to specific rights and obligations in the CRC as relevant to tobacco control.

3 The research underlying this article is part of a study into children's rights and tobacco control carried out between September 2016 and June 2019. 


\section{Vulnerability and Human Rights}

\subsection{The Vulnerable Subject}

Martha Fineman has developed a notion of vulnerability that moves away from classifying sections of society as vulnerable like the elderly, children, women, people with HIV/Aids and rural communities as often seen in human rights law. She proposes to understand vulnerability as a 'universal, inevitable enduring aspect of the human condition that must be at the heart of our concept of social and state responsibility' (Fineman, 2008-2009: 8). Such a notion of vulnerability means that it is both universal and particular at the same time. The universal aspect is that as humans, we are all equally able to suffer and face harm beyond our control. For example, we can all contract infectious diseases or be surprised by natural disasters (Fineman, 2008-2009: 9; Fineman, 2010: 28-29). Indeed, 'as vulnerable subjects we are constantly susceptible to harm' (Peroni and Timmer, 2013: 1058). Yet at the same time, the particular aspect of vulnerability is that these vulnerabilities - as Fineman refers to - differ at individual levels due to a range of socio-, geo-, financial, and political factors (Fineman, 2008-2009: 8-9; Fineman, 2010). Our particular contexts seriously influence the degree to which we are exposed to harm (Fineman, 2010).

The vulnerability of children is both universal and particular (Sandberg, 2015) - also when linked to tobacco-related harm. ${ }^{4}$ For example, exposure to SHS has serious health consequences. According to the wHO, there is no safe level of exposure to SHS and around 890,000 people die each year because of diseases caused by exposure to sHS (WHO, 2018). Everyone, including children, is universally vulnerable to exposure to sHs. However, children as a group are universally more vulnerable than adults. This does not mean they are always a priori the most vulnerable. Depending on the specific conditions, it could be that a child who is not so at risk is less vulnerable than an adult who is more at risk. Nevertheless, generally speaking, children are more vulnerable than adults. For example, their organs including their lungs are under constant development, which means that exposure to SHS is especially detrimental to the healthy development of unborn, newborn and young children (Been et al, 2014; Gispen and Toebes, 2019). Another example of universal vulnerability is smoking itself. The addictive nature of smoking shows everyone, including children, is universally vulnerable to potentially falling victim to

4 This paragraph does not provide an exhaustive overview of all ways in which children are universally or particularly vulnerable to tobacco-related harm but rather elaborates preliminary links to show how the tobacco-related harm experienced by children can be understood in light of Fineman's vulnerability thesis. 
a smoking addiction. ${ }^{5}$ However, as children are universally more vulnerable than are adults, they are also more vulnerable in relation to smoking addictions. For instance, at different stages of childhood, children cannot, or insufficiently, oversee the long-term health consequences of tobacco use because of their evolving capacities. ${ }^{6}$ This is problematic as a US study found that the vast majority of adult daily smokers started before the age of 18 (US Surgeon General, 2012).

Apart from this embodied aspect, there are structural and institutional factors that make some children particularly vulnerable to tobacco-related harm. One of the drivers of smoking and unhealthy lifestyles seems to be socioeconomic status (SES). At least, smoking prevalence is higher among people with low-SEs. Research shows that people with low-SEs are more likely to start smoking and their attempts to quit are less successful (Hiscock et al, 2012). This implies that children from smoking parents are particularly vulnerable. This is especially so because research shows that maternal smoking during pregnancy leads to, amongst others, low-birth weight, preterm birth, reduced lung growth and impaired lung function, and leads to lifelong health and developmental problems (Hofhuis et al., 2003; Makadia et al., 2017; Been et al., 2014; see also Gispen and Toebes, 2019). Naturally, children of smoking caretakers are generally exposed to SHS more often than children of non-smoking parents/caretakers. As newborns and young children are more dependent on caretakers, they are likely to spend more time at home and/or close to the exhaling source, than older children, and are thus even more vulnerable to the negative effects of exposure to sHs. Fineman acknowledges in this context that, 'dependency is most evident when we are infants and children, but while we may be more or less dependent at any given stage, dependency is present in some form and to some degree throughout our lives' (Fineman, 2019: 23). In other words, dependency as such may relate to universal and innate vulnerabilities, but for children of smoking parents this can lead to aggravated factors leading to particular vulnerabilities.

SES has also wider transgenerational and cumulative implications. For example, parental and sibling smoking but also educational achievements, peer pressure, and imitation are structural factors that make some children more vulnerable to tobacco-related harm than others (Mercken et al., 2007;

5 One may question the role of autonomy and free will as tobacco products are, hence smoking is, highly addictive (Schmidt, 2016). Analysis of this normative proposition falls outside the scope of this article.

6 Notably, the notion of evolving capacities is also one of the main principles of the CRC included in Article 5. 
Lorant et al., 2017; Kinnunen et al., 2016; Pförtner et al, 2016; Ncube and Mueller, 2017; Leonardi-Bee et al., 2011; Bektas et al., 2010). Another structural factor that makes children particularly vulnerable is insufficient or lack of regulation of tobacco industry advertisement, promotion and marketing. The industry views children as 'replacement smokers' (Tobacco Free Kids; Gispen and Toebes, 2019) and targets them specifically as their new clientele. However, according to the wHO, comprehensive tobacco marketing bans have been adopted in only 37 countries, which means the large majority of children remain exposed to different forms of tobacco marketing (wHO, 2018), making them particularly vulnerable to pick up smoking. Finally, geographical and socioeconomic factors also influence children's involvement in tobacco farming (WHO 2018, Eriksen et al., 2015) which may lead to a range of adverse health and developmental outcomes including nicotine poisoning and school dropout (WHO 2018; Eriksen et al., 2015; Gispen and Toebes, 2019). In sum, these examples show that children are indeed as mentioned more vulnerable because they are children, but - more importantly - they are particularly vulnerable because of institutional and structural factors.

\subsection{Vulnerability and the State}

In her vulnerability thesis, Fineman developed the notion of a responsive state. She holds that adopting a universal and specific notion of vulnerability enables digging below the surface to reveal underlying biases, assumptions or perhaps even structural constraints in attaining substantive equality (Fineman, 2008-2009: 9). In doing so, the "vulnerable subject" should be at the centre of lawmaking processes as the state has a duty 'to actively structure conditions for equality' (Fineman, 2008-2009: 21). Fineman raises the concern that, in neo-liberal legal cultures, 'it is not seen as requiring legal or political remedy' if states fail to address the needs of those living in poor socioeconomic conditions (Fineman, 2018: 52). Instead, she holds that, 'the social institutions and relationships that a society forms [including the state itself] must transcend not only the specific interests of particular individuals and groups but also have concern for the intergenerational needs of society' (Fineman, 2019: 23).

The idea of a responsive state that addresses structural factors innate to particular vulnerabilities also fits dominant approaches in health law and policy. Toebes and Stronks (2016) hold, for instance, that one should take into account the social determinants of health when designing health laws and policies to improve health equality. In concrete terms, this means that addressing developing tobacco control policies requires addressing the universal and particular vulnerabilities of children. However, the question is whether or not human rights law could act as a springboard to do so. 
As mentioned, Fineman challenges current human rights law as it focuses on the individual and groups of individuals and - in her view - less on the structural and institutional drivers of dependency and resilience (Flegar and Ienema, 2019). ${ }^{7}$ Despite her critique, however, human rights law often speaks of vulnerable groups. Within the remit of the right to health specifically, for example, states are required to allocate sufficient resources to protect vulnerable groups. Failure to do so would result in a violation of the obligation to fulfil the right to health as included in Article 12 of the International Covenant on Economic, Social and Cultural Rights (ICESCR) (CESCR, E/C.12/200o/4, para. $\left.5^{2}\right)$. Moreover, the CESCR interprets non-discrimination as including that:

health facilities, goods and services must be accessible to all, especially the most vulnerable or marginalized sections of the population in law and in fact, without discrimination on any of the prohibited grounds.

CESCR, E/C.12/2000/4, PARA. 12B, EMPHASIS ADDED

The importance of protecting the interests of vulnerable groups in the context of health also features in the core obligations that governments should realise with priority. Governments should adopt a national public health strategy and plan of action in which it 'shall give particular attention to all vulnerable or marginalized groups' (CESCR, E/C.12/200o/4, para. 43(f)). Notably, addressing vulnerability as a matter of non-discrimination is similarly considered a core obligation by the CESCR (CESCR, E/C.12/200o/4, para. 43(a)). While these references show how addressing vulnerability is a matter of priority in international and national health law and policy as based on human rights, these links fail to build factors of resilience to mitigate vulnerability. ${ }^{8}$ Hence, the universal and particular nature of vulnerability as proposed by Fineman seems difficult to implement within the right to health as it is currently developed in international law. At the same time, a development is observed in the work

7 While generally agreeing with the inherent constraints that a group-specific interpretation or labelling of vulnerability bring, I tend to disagree with some of Fineman's principled objections against current human rights law. The justification of human rights is often sought in theories of agency rights. Within this domain, there are theories that support the notion of human rights as such - and although departing from rationality - build on notions of vulnerability quite similar to the universal and particular interpretation of Fineman. Beyleveld and Brownsword, for example, elaborated on the idea of vulnerable agency claiming that all agents are necessarily insecure of the risk to be harmed and their potential to achieve their chosen purposes, either because another agent prevents them or they lack the means, i.e., underlying conditions to achieve their purpose in the first place (2001: 114-115).

8 Flegar and Ienema draw similar conclusions about references to vulnerability in the Convention on the Elimination of Discrimination Against Women (2019). 
of the CRC in particular, which moves away from this group-specific approach to vulnerability and instead seems to address a notion of vulnerability that is quite similar to the way Fineman conceptualises vulnerability. That is to say, the CRC does not formally adopt or enshrine Fineman's notion of vulnerability but instead vulnerability seems to play a role in the CRC that complements Fineman's notion.

While children are both universally vulnerable like everyone else, according to Sandberg, their special rights may be seen as a consequence of their greater vulnerability, a particular vulnerability that they have in common as children' (Sandberg, 2015: 222). Indeed, as Freeman holds, 'vulnerability may justify granting rights to children over and above those which adults have' (Freeman, 2011: 29). Aside from the question of what role vulnerability plays in justifying the entire set of children's rights set out in the CRC, it also plays a role in how the convention should be interpreted and ultimately governed. It thus necessarily plays a role in the types of government action addressing vulnerabilities could give rise to.

Developed in the context of violence against children, the CRC Committee explains the vulnerability of children as that 'at a universal level all children aged o-18 years are considered vulnerable until the completion of their neural, psychological, social, and physical growth and development' (CRC/C/GC13, para. 72f;). It refers to vulnerability as a risk factor and vulnerable situations including exposure to drugs and alcohol as factors that governments need to address in national coordination frameworks (CRC/C/GC13, para. 72). The CRC Committee furthermore holds that governments should identify factors that create vulnerability and address such factors in new laws, regulations, and policies (CRC/C/GC/15, para. 11). Yet, it also stresses that:

[c]ertain groups of adolescents may be particularly subject to multiple vulnerabilities ... All measures taken in respect of legislation, policies and programmes focused on adolescents should take into consideration intersecting violations of rights and the compounded negative effects on the adolescents concerned.

CRC/C/GC20, PARA. 26

These references seem in part a legal translation of Fineman's "responsive state". Indeed, if following Fineman's reasoning, references to vulnerability in the context of the CRC locate states to areas where specific attention or further action is needed to achieve substantive equality. Yet, while addressing vulnerabilities within the traditional human rights framework may be difficult, the notion of vulnerability and the way it emphasises where specific attention or action is needed, can be addressed effectively in the context of the CRC. Article 
3 CRC, which portrays the best interests of the child norm, precisely requires governments to act as responsive states as developed by Fineman. Notably, Article 3 CRC requires governments to put the interest of children, which also depends on a range of innate and context specific factors, at the heart of the interpretation of children's rights and its lawmaking processes.

\section{The Best Interests of the Child as Legal Basis to Address Children's Innate and Specific Vulnerabilities}

\subsection{Different Functions of the Best Interests of the Child Within the CRC}

As mentioned, Article 3 plays a crucial role in translating Fineman's notion of the "responsive state" into the current rights-based framework. Article 3 CRC requires States Parties to the CRC to take all appropriate legal and other measures to ensure that:

in all actions concerning children, whether undertaken by public or private social welfare institutions, courts of law, administrative authorities or legislative bodies, the best interests of the child shall be a primary consideration.

In particular, the CRC Committee outlines that states have an obligation to ensure that the best interests of children are 'appropriately integrated and consistently applied' in every action taken by public institutions that affect them - both directly and indirectly ( $\mathrm{CRC} / \mathrm{C} / \mathrm{GC} 14$, para. 13). The protection of the best interests of the child is, according to the CRC Committee, one of the four general principles of the CRC (CRC/GC/2003/5, para. 12). Article 3 CRC is there with a cornerstone in the interpretation of the CRC.

The CRC Committee interprets that Article 3 CRC encompasses three related functions: it is a substantive right, an interpretative principle, and a procedural norm (CRC/C/GC/14, para 6.). In particular, the last two functions - its role as interpretative principle and as procedural norm - hold clear potential for addressing the embedded and particular vulnerabilities of children in tobacco control law and policies.

3.1.1 Fundamental Interpretative Tool

As a fundamental interpretative tool, the best interests norm reflects a principle that needs to be taken into account when interpreting the application of the individual rights set out in the CRC. The CRC Committee holds that, 'if a legal provision is open to more than one interpretation, the interpretation 
which most effectively serves the child's best interests should be chosen' (CRC/C/GC14, para. 6(b)). As Alston also outlines, the best interests norm can be applied as a mediating principle to guide and balance 'resolving conflicts between different rights where these arise within the overall framework of the Convention [i.e. the CRC]' (Alston, 1994: 16). In case the application of a specific right included in the CRC is open to various interpretations, which is often the case in human rights law, the best interests norm may serve to 'support, justify or clarify a particular approach to issues arising under the [CRC]' (Alston, 1994:15-16). Ultimately, the best interests norm can be understood as an umbrella principle that should 'serve the function of providing an overall framework ... under the shadow of which the remaining provision of the [CRC] are to be applied' (Alston, 1994: 11).

\subsubsection{Procedural Norm}

As a procedural norm, it requires governments to ensure that whenever a decision is made or action is taken that affects children, an impact assessment should be carried out to evaluate the positive and negative impact on a decision or action on the child or group of children (CRC/C/GC14, para. 6(c)). Moreover, the CRC Committee further explains this procedural requirement as including the obligation on the part of states to explain how they reached a certain decision, 'what criteria [the decision] is based on; and how the child's interests have been weighed against other considerations, be they broad issues of policy or individual cases' (CRC/C/GC14, para. 6(c)).

\subsection{Assessing What is in the Best Interests of the Child}

In terms of its scope and content, the best interests norm is a dynamic concept. Within its various functions, but particularly as interpretative tool and procedural requirement, the $\mathrm{CRC}$ Committee holds specifically that, 'the best interests of children in general must be assessed and determined in light of the circumstances of the particular group and/or children in general' (CRC/C/ GC14, para. 32).

While generally the best interests norm applies to both action and omission to act and could refer to actions that affect children directly and indirectly, the best interests norm may be applied differently in these instances. Eekelaar sets out that decision makers which should apply the best interests assessment should focus on 'the issue to be decided rather than on what outcome would be best for the child' in situations in which an action or decision affects (indirect) instead of being about (direct) a child or group of children (Eekelaar, 2016: 99-100). Indeed, according to Flegar and Veys, focusing on the process rather than the outcome is a crucial element of mitigating vulnerability (Flegar 
and Veys, 2017). Yet, Article 3(1) CRC provides a legal basis for all children to see their best interests protected in the adoption of all health laws and policies including tobacco control, and effective remedies should be open in cases where the best interests norm is not applied appropriately and consistently. The question remains how governments should establish what the best interests of the child are and what role vulnerability plays in developing what is in the child's or children's interest in a given context.

3.2.1 Vulnerability and the Best Interests Assessment

To give content and meaning to the norm, the CRC Committee developed the "best interests assessment" in relation to Article 3(1) CRC in particular. Elements to take into account include:

- the child's view and identity;

- preserving the family environment;

- elements of care;

- protection and safety of the child;

- vulnerability;

- the child's right to health;

- the child's right to education (CRC/C/GC14, paras. 53-79).

In light of the CRC, the best interests assessment is a general assessment that should include all factors and elements relevant to the specific case. According to the CRC Committee, the purpose of the test is to reinforce the effective enjoyment of the rights contained in the CRC and to support the holistic development of the child and this should be reflected in carrying out a case-by-case assessment (CRC/C/GC14, paras. 80, 82). Within the best interests assessment frame, the CRC Committee underscores the importance of taking into account the particular vulnerabilities of children. The CRC Committee elaborates:

[t] he best interests of a child in a specific situation of vulnerability will not be the same as those of all the children in the same vulnerable situation. Authorities and decision-makers need to take into account the different kinds and degrees of vulnerability of each child as each child is unique and each situation must be assessed according to the child's uniqueness.

CRC/C/GC14, PARA. 76

In other words, promoting and protecting the best interests of the child necessarily requires addressing structural factors that make some children particularly vulnerable as compared to others. However, doing so might clash with other interests - in both an individual and general context. 
Based on Article 3 CRC, all children have the right that their best interests shall be 'a primary consideration' in all actions concerning them. Yet, this raises the question of what it means that the best interests norm should be a primary consideration and how that relates to other interests involved. The CRC and the interpretation of the CRC Committee show two approaches. First, Article 21 CRC explicitly prescribes that the best interests of the child is the paramount consideration in adoption cases. The CRC Committee builds on that and takes a slightly wider approach, stating that the best interests of the child is the paramount consideration in issues other than adoption as well. While the Committee does not specify this explicitly, it seems as if in individual family and migration law cases - such as adoption - the best interests norm should be considered the paramount consideration. However, the Committee also acknowledges that protecting and promoting the best interests of the child may conflict with other issues involved (CRC/C/GC14, para. 39). Indeed, the second approach visible in the interpretation of the CRC Committee shows that the best interests of the child puts extra weight in a balancing exercise typical to settling fundamental rights clashes but does not a priori trump other considerations. According to Alston, reference to $a$ paramount consideration instead of the paramount consideration in the text of Article 3 CRC evidences that the best interests of the child should not 'be considered as the single overriding factor' (1994: 12). This is, according to Alston, unavoidable given the central and thus very diverse role of Article 3 CRC in the convention (Alston, 1994: 12-13). The CRC Committee holds that, as relevant also to issues of public policy including tobacco control, 'the best interests of the child - once assessed and determined - might conflict with other interests or rights' (CRC/C/GC14, para. 39). One can thus imagine examples where, while observing Article 3 CRC, other interests than those of the child prevail (Alston, 1994: 13). However, Alston also notes that this flexibility imposes 'a burden of proof on those seeking to achieve such non-child-centered result to demonstrate that, under the circumstances, other feasible and acceptable alternatives do not exist'. The slight relativity found in applying Article 3 CRC can thus not result in unlawfully mitigating the position of children.

In case the interests of children conflict with other interests, which is most likely the case in adopting public policy including tobacco control measures, conflicts have to be resolved on a case-by-case basis (CRC/C/GC14, para. 39). According to the CRC Committee, the best interests of the child requires that the 'child's interests have high priority and [are] not just one of several considerations. Therefore, a larger weight must be attached to what serves the child best' (CRC/C/GC14, para. 39). In other words, balancing children's interests with other rights and interests justifies that their interests put more 
'normative weight' on the scale than that of other interests. As vulnerability plays a central role in the best interests assessment, it is also important in determining the priority given to the position and interests of children in issues of broad law and policy. In concrete terms, this could mean that in relation to tobacco control the best interests of the child may have a decisive role in regulating marketing strategies of tobacco companies, as these strategies are often specifically targeted at children despite, for example, their trade interests.

Nevertheless, while the legal structure of the best interests norm are clear and its relevance to policy and practice are broadly emphasised, the specific meaning the principle may have in relation to health law and policy including tobacco control is more difficult to assess (Gispen and Toebes, 2019). Indeed, the dynamic but rather vague nature of the principle constitutes its main criticism (Sutherland, 2016). The exact approach that an architectonic principle like the best interests norm would impose on issues of public policy remains particularly unclear and therefore, in law, somewhat speculative. This is partly because the norm has been mostly applied and therefore contextualised in individual cases in areas such as family and migration law (e.g. Alston, 1994: 12; Kalverboer and Zijlstra, 2010). Yet, one may question if one should solely rely on law for developing the best interests norm or instead should take into account other disciplines such as behavioural sciences. Kalverboer and Zijlstra, for example, developed a questionnaire based on the CRC to identify what is in the best interests of a child in a given situation (Kalverboer and Zijlstra, 2010). Although societal aspects, including a safe and healthy environment, are included in the tool (Kalverboer and Zijlstra, 2010: 13-14), the questionnaire also seems more focussed on individual cases than immediately relevant to understanding the normative scope and content of the best interests norm in public policy. Until now, it therefore seems as if - at least within law - the broader potential of the norm still largely depends on the interpretation of specific rights included in the CRC.

\subsection{Towards a Rights Framework}

Previous analysis has shown the relevance of human rights, and children's rights in particular, in tobacco control measures (Toebes et al., 2018; Gispen and Toebes, 2019). The Articles jointly show that a range of rights is relevant. In particular, the right to health, the right to life, survival and development, the right to be heard, and the right to information, the protection against exploitation and the best interests of the child are central norms in developing tobacco control measures in light of children's rights. Based on the rights mentioned, governments have to provide for adequate prenatal care, ensure clean and safe 
environments including tobacco control measures, regulate the tobacco industry such that their activities no longer harm children's rights and interests, ensure access to health-related information, and adopt demand reduction and cessation measures (Gispen and Toebes, 2019). Protection of the best interests of the child is a cross-cutting norm in the area of tobacco control.

As was seen under the best interests assessment, the CRC Committee draws a clear link between the right to health of Article 24 CRC and the best interests of the child norm. At times, it even does so specifically in relation to tobacco. For example, in further delineating the normative scope and content of the right to health included in Article 24 CRC, the Committee:

urges States to place children's best interests at the centre of all decisions affecting their health and development, including ... the development and implementation of policies and interventions that affect the underlying determinants of their health. [This includes, amongst others that] the best interests of the child should ... influence the development of policies to regulate actions that impede the physical and social environments in which children live, grow and develop.

CRC/C/GC/15, PARA. 13(C)

Moreover, in their law, policy and programme-making processes, states should focus their attention on 'children in disadvantaged situations and underserved areas ... [and] should identify factors at national and subnational levels that create vulnerabilities for children or that disadvantage certain groups of children' (CRC/C/GC/15, para. 11). Moreover, by all means, governments should protect children from any form of discrimination that undermines their health (CRC/C/GC/15, para. 8), which is, in line with Fineman's approach, the most important factor to mitigate vulnerability in the first place. In many ways, the tobacco supply chain affects child health and development - in particular in their physical and social environments. Indeed, governments should continuously assess the impact of macroeconomic policy decisions on children's health, taking into account in particular the impact of policy decisions on the health of children in vulnerable situations (CRC/C/GC/15, para. 105). This fits squarely into the importance of carrying out child rights impact assessments (CRIA s) as part of state obligations under Article 3 CRC.

In addition, in further interpreting the best interests of the child norm itself, the CRC Committee holds that 'the child's right to health ... and his or her health condition are central in assessing the child's best interest' (CRC/C/GC/14, para. 77). The Committee emphasises the importance of access to health-related information as relevant to their interests. With regards to adolescent health in particular, the committee stresses: 
States parties have the obligation to ensure that all adolescents, both in and out of school, have access to adequate information that is essential for their health and development in order to make appropriate health behavior choices. This should include information on use and abuse of tobacco, alcohol and other substances ...

CRC/C/GC/14, PARA. 78

As was mentioned above, children are frequently exposed to, and specifically the subject of, tobacco marketing. Their increased vulnerability to fall victim to the marketing and advertisement strategies of the tobacco industry warrants specific attention within a vulnerability and human rights context. This is especially so because health is an essential component of assessing a child's best interests. Notably, Sandberg emphasises the importance of participation of children based on their evolving capacities as an important factor to move away from paternalistic approaches to vulnerability within the remit of the CRC and to move towards more capacity-based oriented conceptions of addressing the particular vulnerabilities of children (Sandberg, 2015).

With regard to the right to life, survival and development, the CRC Committee underscores that " $\mathrm{i}] \mathrm{n}$ the assessment and determination of the child's best interests, the State must ensure full respect for his or her inherent right to life, survival and development' (cc/C/GC/14, para. 42). Doing so should contribute to creating 'an environment that respects human dignity and ensures the holistic development of every child' (CRC/C/GC/14, para. 42). As mentioned, children in different contexts and due to different factors are particularly vulnerable across the entire tobacco supply chain, leading to clear detrimental health and developmental risks across all stages of childhood. Alternatively, when further elaborating on the rights of children in early childhood - in which Article 6 CRC plays a central role - the CRC Committee holds that the best interests of the child has both an individual and group component, of which the latter includes addressing policy areas that may indirectly impact on children's life, survival and development, such as the environment (CRC/C/GC/7/Rev.1). Tobacco control measures to support the life, survival and development of children squarely fits into this framing.

Moreover, the obligations on the part of the government are extended to cover the private sector insofar as, according to the CRC Committee, governments have an obligation to 'ensure that the interests of the child have been assessed and taken as a primary consideration in decisions and actions taken by the private sector, including those providing services, or any other private entity or institution making decisions that concern or impact on a child' (CRC/C/GC14, para. 14(c)). Tobacco as such has a clear impact on children as do the marketing and labour decisions and actions of the tobacco industry. A 
universal and particular vulnerability claim is also visible in this context. For example, geo- and economic factors may make children from low- and middle-income countries particularly vulnerable for being included in informal industries and agriculture including tobacco farming. Hence, in this interpretation of the best interests norm, the government must regulate the private sector such that their activities and decisions no longer negatively impact on children's rights and wellbeing and should counter any form of exploitation including those related to their vulnerability. The CRC Committee, however, in this case, seems clearly to extend the scope of Article 3(1) CRC and its relevance to the private sector: the text of Article 3(1) CRC refers to all public or private social welfare institutions and not to the private sector in general.

\section{Conclusion}

The central purpose of this article was to reflect on the usefulness of vulnerability in calling for additional rights protection in general, and specifically as relevant for protecting children against tobacco-related health infirmity. It posed this question against the backdrop of, on the one hand, health sciences research relying on children's vulnerability in proposing policy interventions, and on the other hand, the scholarship of Fineman and others building on her theory criticising vulnerability within the context of the human rights discourse.

The article showed that the best interests of the child norm as included in Article 3 CRC provides for a clear legal framework to address the universal - and especially the particular - vulnerabilities of children. In fact, Article 3 CRC seems to require from states most of what Fineman has in mind with her vulnerability thesis and corresponding responsive state. Hence, Article 3 CRC seems overall a suitable 'solution' to Fineman's principled problems with the notion of vulnerability in human rights law. As such, universal and particular vulnerabilities of children in relation to tobacco-related harm can in fact be a springboard into rights protection but are not the principle legal source that require governments to break down structural health inequalities. In other words, vulnerability may be the end but seems unfitting as a means sufficiently to build factors that mitigate vulnerability. Indeed, the best interests of the child norm provides for a legal basis that works as normative flashlight to guide governments to universal and in particular child developmental, medical and social determinants that need to be at the heart of the lawmaking process when directly or indirectly influencing their wellbeing. More specifically, this means that governments have to carry out impact assessments in all their law, policy and programme making, including on issues of broad policy such 
as health and tobacco control. Despite its central role and clear potential, however, the best interests norm also comes with limitations that should be the subject of additional analysis. In order to address adequately the vulnerabilities of children in future lawmaking processes, it is important to expand our understanding of the potential of Article $3 \mathrm{CRC}$ as a guiding norm in matters of socioeconomic (health) law and policy. This will result in new knowledge on both the role of vulnerability and the content and meaning of the best interests norm in human rights law.

\section{Acknowledgement}

The research underlying this article was carried out as part of a three-year research project into children's rights and tobacco control funded by the Dutch Cancer Society. The funding body did not play any role in drafting the study design, the data collection and analysis, nor in the writing or reviewing of this manuscript.

\section{References}

Alston, P., "The Best Interests Principle: Towards a Reconciliation of Culture and Human Rights", International Journal of Law and the Family 1994 (8(1)), 1-25.

Been, J.V., Nurmatov, U.B., Cox, B., Nawrot, T.S., Schayck, van, C.P., Sheikh, A., "Effect of Smoke-Free Legislation on Perinatal and Child Health: A Systematic Review and Meta-Analysis", Lancet 2014 (383(9928)), 1549-1560.

Bektas, M., Ozturk, C., Armstrong, M., "An Approach to Children's Smoking Behaviors Using Social Cognitive Learning Theory", Asian Pacific Journal of Cancer Prevention $2010(11(4)), 1143^{-1149 .}$

Beyleveld, D. and Brownsword, R., Human Dignity in Bioethics and Biolaw (Oxford: Oxford University Press, 2001).

Eekelaar J., "Two Dimensions of the Best Interests Principle: Decisions About Children and Decisions Affecting Children", in E.E. Sutherland and L.A.B. Macfarlane (eds.), Implementing Article 3 of the United Nations Convention on The Rights of the Child - Best Interests, Welfare and Well-being (Cambridge: Cambridge University Press, 2016).

Eriksen, M., Mackay, J., Schluger, N., Gomeshtapeh, F.I., Drope, J., The Tobacco Atlas (5th edn., Atlanta: American Cancer Society and World Lung Foundation, 2015).

Fineman, M.A., "The Vulnerable Subject: Anchoring Equality in the Human Condition", Yale Journal of Law and Feminism 2008-2009 (20(1)), 1-23. 
Fineman, M.A., "The Vulnerable Subject and the Responsive State", Public Law \& Legal Theory Research Paper Series 2010 (Research paper no: 10-130).

Fineman, M.A., "Injury in the Unresponsive State: Writing the Vulnerable Subject into Neo-Liberal Legal Culture", in A. Bloom, D.M. Engel and M. McCann (eds.), Injury and Injustice: The Cultural Politics of Harm and Redress (Cambridge: Cambridge University Press, 2018).

Fineman, M.A., "Vulnerability and Social Justice", Valparaiso University Law Review 2019.

Flegar, V.L.B., "Who is Deemed Vulnerable in the Governance of Migration? Unpacking UNHCR's and IOM's Policy Label for Being Deserving of Protection and Assistance", Asiel \& Migratie 2018 (8), 374-382.

Flegar, V.L.B., Iedema, E., “The Use of the 'Vulnerability' Label by the Committee on the Elimination of Discrimination Against Women: Protecting or Stigmatizing Women and Girls in the Forced Migration Context?", Brill Open Law (2) 2019, 1-41.

Flegar, V.L.B., Veys, M.N., “De Europese verplichting voor procedurele waarborgen in de asielprocedureendeNederlandseimplementatievanuitkwetsbaarheidsperspectief", Journaal Vreemdelingenrecht 2017 (2), 28-49.

Freeman, M., "The Value and Values of Children's Rights", in A. Invernizzi and J. Williams (eds.), The Human Rights of Children - From Vision to Implementation (Routledge, 2011).

Gispen, M.E.C., Toebes, B.C.A., "The Human Rights of Children in Tobacco Control”, Human Rights Quarterly 2019 (41), 340-373.

Hiscock, R., Bauld, L., Amos, A., Fidler, J.A., Munafo, M., "Socioeconomic status and smoking: a review", Annals of the New York Academy of Sciences 2012 (1248(1)), 107-123.

Hofhuis, W., Jongste, de, J.C., Merkus, P.J., "Adverse Health Effects of Prenatal and Postnatal Tobacco Smoke Exposure on Children", Arch Dis Child 2003 (88(12)), 1086-9o.

Kalverboer, M. and Zijlstra, E., Het belang van het kind in het Nederlands recht: Voorwaarden voor ontwikkeling vanuit een pedagogisch perspectief (Amsterdam: SWP, 2010).

Kinnunen, J.M., Lindfors, P., Rimpelä, A., Salmela-Aro, K., Rathmann, K., Perelman, J., Federico, B., Richter, M., Kunst, A.E., Lorant, V., "Academic Well-being and Smoking Among 14- to 17-year-old schoolchildren in Six European Cities", Journal of Adolescence 2016 (50), 56-64.

Leonardi-Bee, J., Jere, M.L., Britton, J., "Exposure to Parental and Sibling Smoking and the Risk of Smoking Uptake in Childhood and Adolescence: A Systematic Review and Meta-Analysis", Thorax 2011 (66(10)), 847-855.

Lorant, V., Rojas, V.S., Robert, P.O., Kinnunen, J.M., Kuipers, M.A.G., Moor, I., Roscillo, G., Alves, J., Rimpelä, A., Federico, B., Richter, M., Perelman, J., Kunst, A.E., "Social 
Network and Inequalities in Smoking Amongst School-Aged Adolescents in Six European Countries", International Journal of Public Health 2017 (62(1)), 53-62.

Makadia, L.D., Roper, P.J., Andrews, J.O., Tingen, M.S., "Tobacco Use and Smoke Exposure in Children: New Trends, Harm and Strategies to Improve Health Outcomes", Curr Allergy Asthma Rep 2017 (17(8)), 1-15.

Mercken, L., Candel, M., Willems, P., Vries, de, H., "Disentangling Social Selection and Social Influence Effects on Adolescent Smoking: The Importance of Reciprocity in Friendships", Addiction 2007 (102(9)), 1483-1492.

Ncube, C.N., Mueller, B.A., "Daughters of Mothers Who Smoke: A Population-based Cohort Study of Maternal Prenatal Tobacco Use and Subsequent Prenatal Smoking in Offspring", Paediatric and Perinatal Epidemiology 2017 (31(1)), 14-20.

Peroni, L., Timmer, A., "Vulnerable Groups: The Promise of an Emerging Concept in European Human Rights Convention Law", International Journal of Constitutional Law 2013 (11(4)), 1056-1085.

Pförtner, T., Hublet, A., Warrer Schnohr, C., Rathmann, K., Moor, I., de, Looze, M., Baška, T., Molcho, M., Kannas, L., Kunst, A.E., Richter, M., "Socioeconomic Inequalities in the Impact of Tobacco Control Policies on Adolescent Smoking. A Multilevel Study in 29 European countries", Addictive Behaviors 2016 (53), 58-66.

Sandberg, K., "The Convention on the Rights of the Child and the Vulnerability of Children", Nordic Journal of International Law 2015 (84(2)), 221-247.

Schmidt, A.T., "Withdrawing Versus Withholding Freedoms: Nudging and the Case of Tobacco Control", The American Journal of Bioethics 2016 (16(7)), 3-14.

Sutherland E.E., "Article 3 of the United Nations Convention on the Rights of the Child: The Challenges of Vagueness and Priorities", in E.E. Sutherland and L.E. Barnes (eds.), Implementing Article 3 of the United Nations Convention on The Rights of the Child - Best Interests, Welfare and Well-being (Cambridge: Cambridge University Press 2016).

Tobacco Free Kids, Tobacco Company Marketing to Kids. Available at: https://www. tobaccofreekids.org/research/factsheets/pdf/ooo8.pdf. Accessed 18 June 2019.

Toebes, B., Gispen, M.E.C., Been, J.V., Sheikh, A., "A Missing Voice: The Human Rights of Children to a Tobacco-Free Environment", Tobacco Control 2018 $(27(1)), 3-5$.

Toebes, B.C.A., Stronks, K., "Closing the Gap: A Human Rights Approach Towards Social Determinants of Health", European Journal of Health Law 2016 (23(5)), 510-524.

United Nations Committee on Economic, Social and Cultural Rights, General Comment No. 14: The Right to the Highest Attainable Standard of Health (Art. 12) (Geneva: United Nations 2000). E/C.12/200o/4.

United Nations Committee on the Rights of the Child, General Comment No. 5: General Measures of Implementation of the Convention on the Rights of the Child (Arts. 4, 42 and 44, para. 6) (Geneva: United Nations 2003). CRC/C/GC/2003/5. 
United Nations Committee on the Rights of the Child, General Comment No. 7: Implementing Child Rights in Early Childhood (Geneva: United Nations 2005). CRC/C/GC/7/Rev.1.

United Nations Committee on the Rights of the Child, General Comment No. 13: The Right of the Child to Freedom from All Forms of Violence (Geneva: United Nations 2011). CRC/C/GC13.

United Nations Committee on the Rights of the Child, General Comment No. 14: The Right of the Child to Have His or Her Best Interests Taken as a Primary Consideration (Art. 3, para. 1) (Geneva: United Nations 2013). CRC/C/GC/14.

United Nations Committee on the Rights of the Child, General Comment No. 15: The Right of the Child to the Enjoyment of the Highest Attainable Standard of Health (Art. 24) (Geneva: United Nations 2013). CRC/C/GC/15.

United Nations Committee on the Rights of the Child, General Comment No. 20 : Implementation of the Rights of the Child during Adolescence (Geneva: United Nations 2016). CRC/C/GC2O.

US Department of Health and Human Services, Preventing Tobacco Use Among Youth and Young Adults: A Report of the Surgeon General (U.S. Department of Health and Human Services, Centers for Disease Control and Prevention, National Center for Chronic Disease Prevention and Health Promotion, Office on Smoking and Health, 2012).

Virokannas, E., Liuski, S., Kuronen, M., "The contested concept of vulnerability - a literature review", European Journal of Social Work 2018, 1-13.

wHo, Factsheet Tobacco (last updated 9 March 2018). Available at: http://www.who. int/news-room/fact-sheets/detail/tobacco. Accessed 18 June 2019. 